\title{
Kapitel 14: Martyrion, Homologia und Askese
}

Das Eintreten für Gott und für den christlichen Glauben, das Zeugnis Christi, findet sich in den byzantinischen Heiligenviten unserer Zeit in drei Abstufungen, nämlich als Opfertod (Martyrium), Bekenntnis (Homologia) und mühevolle Übung (Askese) ${ }^{1}$. Vor allem Opfertod und Bekenntnis, bisweilen aber auch die Askese sind dabei spezifischer Ausdruck des allgemeinen und übergeordneten Motivs der „Verfolgung“, das sich bereits im AT findet, mit der Verfolgung Jesu in den Evangelien fortgesetzt und in der byzantinischen hagiographischen Literatur weitergeführt wird ${ }^{2}$. Andeutungen der Verfolgung des Heiligen lassen sich in den Viten vielerorts greifen; sie spielen bisweilen in die bereits behandelten Motive des Rückzugs und der Wanderschaft hinein und führen in der Regel zu Martyrium, Bekenntnis oder Askese hin.

Die Darstellung des Martyriums findet sich schon in der urchristlichen Überlieferung $^{3}$, geht aber vor allem auf die Märtyrerakten der Verfolgungszeit zurück $^{4}$. Der Märtyrer bezeugt seinen christlichen Glauben mit seinem eigenen Blut und Leben ${ }^{5}$. Nach dem Ende der Verfolgungen (Toleranzedikt 311; Sieg des Licinius über Maximinus Daia 313) und mit der zunehmenden Ausbreitung des Christentums innerhalb des Reiches ging die Zahl der „echten Märtyrer", also derjenigen, die in direkter Nachahmung des Blutzeugnisses Christi für ihr Bekenntnis zum christlichen Glauben mit dem Tode bestraft wurden, drastisch zurück, wiewohl sich auch in der hier behandelten Zeit noch solche Beispiele finden $\operatorname{lassen}^{6}$.

1 Vgl. dazu bes. Delehaye, Sanctus 109-121; LThK 4 (1995) 1329 s, v. „Heiligsprechung". In diesem Punkt überschneiden sich die Topoi des „Martyriums“ mit denen der „Tugenden“, zu letzteren s. bereits oben Kap. 11, S. 205-212.

2 Vgl. LThK 10 (2001) 647-649 s. v.

3 Vgl. Apg 7. 1-59 (Martyrium Stephani Protomartyris).

4 Zur gegenseitigen Beeinflussung von Märtyrerakten und Heiligenvita vgl. Prießnig, Formen 9496. Zu älteren Vorbildern vgl. Reitzenstein, Wundererzählungen 46-49; Lietzmann, Alte Kirche IV 114f. [1106f.]; zu westlichen Beispielen vgl. Scheibelreiter, Gegner 65. 77-79.

5 Vgl. Onasch, Ostkirche 262f. s. v. "Märtyrer"; Angenendt, Heilige 35-38. 62-65.

6 Der $\mathrm{Hl}$. legte nun meist vor einem nichtchristlichen Herrscher oder auch einem vermeintlich nicht rechtgläubigen (häretischen) byz. Käiser mit seinem Blut und Leben Zeugnis für den christlichen Glauben ab. Vgl. dazu auch Dummer, Hagiographie 291. 


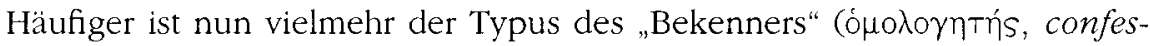
sor) anzutreffen. Der Bekenner bezeugt den Glauben ,unter Martern, aber ohne zu sterben, unter gesellschaftlicher Ächtung, Güterkonfiszierung u. a." J Jede Art von kirchenrechtlicher und besonders strafrechtlicher Verfolgung, vor allem jeder Konflikt des Heiligen mit dem Kaiser und der Obrigkeit und jedwede Art von Bestrafung des Heiligen konnte somit in der literarischen Darstellung der Vita als Bekenntnis interpretiert werden. Insbesondere galt das Eintreten für den rechten Glauben in Zeiten häretischer Verirrungen als Bekenntnis, man denke hier etwa an Maximos Confessor ${ }^{8}$ oder Theophanes Homologetes ${ }^{9}$, die „Bekenner".

Schließlich begegnen wir in diesem Zusammenhang auch dem Asketen. Die Askese stellt zwar die niedrigste, aber doch auch eine eigene Form der Zeugenschaft Christi dar. ${ }^{10}$ Der Asket erleidet freiwillig ein unblutiges Martyrium ${ }^{11}$ durch die Abtötung (véкpwoıs, mortificatio) seiner fleischlichen Begierden und Bedürfnisse und das Üben (ảokềv) möglichst extremer Formen der Enthaltsam-

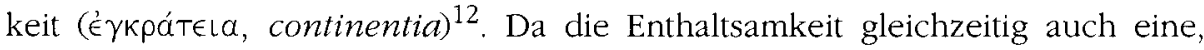
nach unseren Quellen sogar die höchste Tugend ist, ergeben sich an dieser Stelle starke Überschneidungen zu den oben bereits behandelten Tugenden des Heiligen $^{13}$. Im Rahmen der Komposition der byzantinischen Heiligenviten spielt die Darstellung der Askese als der am ehesten aus eigener Kraft realisierbaren Form der Zeugenschaft Christi eine wichtige Rolle.

7 Vgl. Onasch, Ostkirche 263 s. v. „Märtyrer“; Delehaye, Sanctus 95-121; Winkelmann, Frühes Christentum 93; Angenendt, Heilige 55-61.

8 Vgl. dazu u. a. ODB 2, 1323f.; W. Brandes, in: PMBZ, Prolegomena 171-179; dens., „Juristische“ Krisenbewältigung im 7. Jahrhundert? Die Prozesse gegen Martin I. und Maximos Homologetes, in: FM 10 (1998) 141-212; Winkelmann, Streit passim.

9 Vgl. ODB 3, 2063 s. v. "Theophanes the Confessor" (mit weiterer Literatur); I. Rochow, Byzanz im 8. Jahrhundert in der Sicht des Theophanes, Berlin 1991 (BBA 57) bes. 37-41.

10 Vgl. Winkelmann, Frühes Christentum 96; Kazhdan, Miracle Workers 76; Calendine, Theosis 6 15 Anm. 20. 77-80; Angenendt, Heilige 55-61. 66-68; auch Jost, Patrozinien 348-368; Mango, Saints 272-274. Zu Vorläufern vgl. Reitzenstein, Wundererzählungen 44f. u. ö; Bieler, Theios aner I, 60-68.

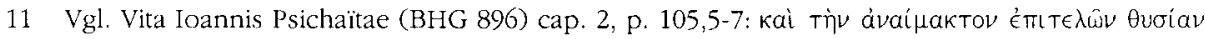

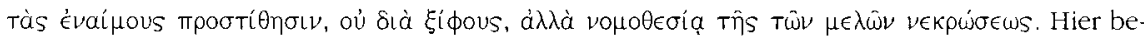
züglich der Erziehung des jungen Ioannes durch den Vater geäußert, trifft dies jedoch den Kern der damals gängigen Vorstellung von Askese.

12 Zur Geschichte dieser Übung vgl. auch E. Fehrle, Die kultische Keuschheit im Altertum, Gießen 1910 (Religionsgeschichtliche Versuche und Vorarbeiten 6); P. Brown, The Body and Society, New York 1988 (dt. Ausgabe: Sexuelle Entsagung, Askese und Körperlichkeit am Anfang des Christentums, aus d. Engl. v. M. Pfeiffer, München-Wien 1991.

13 S. dazu bereits oben Kap. 11: „Tugenden“, S. 205-212. 
Martyrium, Bekenntnis und Askese können auch miteinander verbunden, nebeneinander oder jeweils wiederholt auftreten: Dem Martyrium geht ohnehin im Regelfall ein Bekenntnis voraus, und umgekehrt stellt ein Bekenntnis im Kern einen, häufig zwar verkürzten, Märtyrerprozeß dar, dem lediglich die Hinrichtung aus Glaubensgründen, eben das eigentliche Martyrium, fehlt. Auf der anderen Seite kann das Bekenntnis als asketische Übung des Heiligen dargestellt werden, deren Krönung im Martyrium besteht.

\section{Martyrion}

In der Vita des Michael Sabbaïtes, die innerhalb der Vita des Theodoros von Edessa (BHG 1744) überliefert wird ${ }^{14}$, findet sich folgende, längere Darstellung eines Martyriums ${ }^{15}$ : Zunächst findet eine Disputation über den rechten Glauben zwischen Michael Sabbaites auf der einen und dem Kalifen 'Abd al-Malik und einem Juden, offenbar einem Berater des Kalifen, auf der anderen Seite statt. Michael bekennt sich dabei zum Christentum und wird daraufhin der Folter unterworfen. Er muß nun barfuß auf glühenden Kohlen stehen und überlebt auf wunderbare Weise die Einnahme eines Gifttranks, der ihm verabreicht worden war (cap. 29). Michael bekennt sich in der Folge noch mehrfach zu seinem Glauben. Schließlich verurteilt ihn der Kalif zum Tode und ordnet seine Enthauptung vor den Toren der Stadt (Jerusalem) an (cap. 30). Der Befehl des Kalifen wird ausgeführt und Michael wird enthauptet (cap. 32).

Einer der bekanntesten - vielleicht sogar der bekannteste - Märtyrer im betrachteten Zeitraum ist Stephanos der Jüngere vom Auxentiosberg, der unter Konstantin V. zu Tode kam ${ }^{16}$. Die Vita des Stephanos (BHG 1666) widmet sich über längere Strecken ${ }^{17}$ der Auseinandersetzung zwischen Kaiser Konstantin und Stephanos bis hin zu dessen Martyrium. Stephanos widersetzt sich in dieser Darstellung dem auf Betreiben Konstantins auf dem Konzil von Hiereia 754 synodal verabschiedeten Verbot der Ikonenverehrung. Er weigert sich, auch auf mehrfache Aufforderung hin, die Beschlüsse des Konzils zu unterschreiben. Stephanos wird daraufhin Opfer von Verleumdungen und Intrigen, die gegen ihn gerichtet sind. Schließlich läßt ihn der Kaiser unter einem Vorwand festnehmen und im Philippikoskloster in Chrysopolis internieren. Stephanos wird dort von

14 Vgl. dazu PMBZ: \# 5003 (Michael Sabbaites) mit weiteren Quellen zu Michael und Literatur zur Problematik der Lebensgeschichte des Michael Sabbaïtes. S. dazu noch unten S. $388 f$.

15 Vita Theodori Edess. (BHG 1744) cap. 25-32, p. 21-29

16 Vgl, dazu Rochow, Konstantin 60f.

17 Vita Stephani iun. (BHG 1666) cap. 24-69, p. 119-170. 
Bischöfen und kaiserlichen Beamten aufgesucht, die mit ihm über die Ikonenverehrung diskutieren. Dabei hat er mehrfach Gelegenheit, sich für den rechten Glauben (nämlich die Ikonenverehrung) einzusetzen, also sein Bekenntnis abzulegen. Er wird daraufhin vom Kaiser auf die Insel Prokonnesos verbannt. Dann läßt der Kaiser Stephanos in die Hauptstadt bringen und führt dort selbst ein Gespräch mit ihm über die Ikonenverehrung. Stephanos legt vor dem Kaiser ein weiteres Mal sein Bekenntnis (für die Ikonenverehrung) ab, woraufhin Konstantin ihn im Praitorion festsetzen läßt. Nach weiteren Zwischenspielen ${ }^{18}$ kommt es schließlich zur „Hinrichtung“ des Stephanos, die allerdings eher den Eindruck eines Lynchmordes durch den Konstantinopler Mob erweckt ${ }^{19}$, der durch das Eintreten für den rechten Glauben bzw. durch eine angebliche Order des Kaisers nur recht dürftig motiviert ist. Stephanos wird nämlich von einer Menschenmenge aus dem Praitorion geschleift und ermordet ${ }^{20}$ : „Als er nun durch das erste Tor des Praitorions gezogen wurde und den Eingang der dort befindlichen heiligen Kirche des heiligen Märtyrers Theodoros erreichte, da wandte er die Hände zur Erde, neigte ein wenig das Haupt und hob seinen Blick zum Himmel, um dem Märtyrer die geziemende und letzte Verehrung zu erweisen. Als nun einer der Gottlosen, der ganz und gar den Teufel im Leib hatte, den Heiligen dies tun sah, rief er mit Gebrüll: 'Siehe, der Nicht-zu-Erinnernde (sc. Mönch ${ }^{21}$ ) will wie ein Märtyrer sterben!' Und er lief zu den an diesem Ort stehenden Feuerspritzen, die man Siphone nennt, und nahm von einer von diesen ein großes Holzstück, das man Antion nennt, und voller Jähzorn wandte er sich um und erreichte den von der Menge geschleiften Heiligen und schlug ihm auf die Schädeldecke wie einem Hund - in diesem Augenblick hatte er den Heiligen ermordet."

Ein echtes Martyrium wird auch in der Vita des Euthymios von Sardeis (BHG 2145) über sechs Kapitel hin sehr ausführlich dargestellt, denn der Heilige verstirbt dort an den Folgen der körperlichen Züchtigung ${ }^{22}$ : Euthymios, der an der Ikonenverehrung festhält, wird ergriffen und vom Kaiser (Theophilos) einem Verhör unterzogen. Er wird geschlagen und zur Verbannung auf die Insel Hagios Andreas beim Kap Akritas verurteilt. Eine Eskorte bringt ihn nach Hagios Andreas, wo er von mehreren hohen kaiserlichen Beamten (nämlich dem Logo-

18 Vita Stephani iun. (BHG 1666) cap. 57-68; p. 158-169.

19 Vgl Rochow, Konstantin 61.

20 Vita Stephani iun. (BHG 1666) cap. 68, p. $168 \mathrm{f}$

21 Angeblich habe Konstantin V. unter anderem diesen Begriff (ả $\mu \nu \eta \mu o ́ v \in u T o s$ ) für einen Mönch verwendet, vgl. Rochow, Konstantin 59. Das scheint auf den Begriff der $\mu \nu \eta\{\eta \eta$ im Kontext der Heiligenverehrung anzuspielen, daher eigentlich "der, dessen nicht (im Gottesdienst) gedacht werden soll", folglich "der Unheilige".

Vita Euthymii Sard. (BHG 2145) cap. 14,274-20,399, p. 41-49. 
thetes des Dromos, dem Kanikleios und dem Manglabites) erneut befragt und mit insgesamt 120 Peitschenhieben gezüchtigt wird. Anschließend lebt er noch acht Tage, erliegt aber schließlich den Folgen der Tortur und stirbt.

Obgleich literarisch ungewöhnlich ${ }^{23}$, ist die Darstellung des Todes von Maria der Jüngeren in deren Vita (BHG 1164) ebenfalls in vielen Punkten dem Martyrium nachgebildet. Die längere Entwicklung zu ihrem Tode hin wird in der Vita als ein teuflischer Plan gezeichnet, eine "letzte Versuchung“ ( $\pi \in t \rho a \sigma \mu o ́ s)$ Satans ${ }^{24}$ : Dieser stiftet zunächst Helene und Alexios, die Geschwister von Marias Ehemann Nikephoros, dazu an, Maria bei ihrem Mann zu verleumden, sie unterhalte eine ehebrecherische Beziehung zu dem Diener Demetrios. Daraufhin wird sie von ihrem Mann einem strengen Verhör unterzogen, in dem sie ihre Unschuld beteuert und sich zu ihrer ehelichen Treue "bekennt". Schließlich geht es in dem Gespräch aber auch um ihre Freigebigkeit, also um ihre Tugend, die nach Ansicht des Nikephoros das Haus in den Ruin zu stürzen droht. Nikephoros stellt anschließend Wachen vor dem Schlafgemach seiner Frau auf und läßt auch eine Dienerin verhören und auspeitschen, kann aber kejnerlei Beweis für Marias Untreue finden. Nikephoros verschärft daraufhin Marias Bewachung und Beobachtung und macht ihr damit das Leben schwer, woraufhin sie erkrankt. Dann kam die Fastenzeit heran, und Maria enthielt sich des Fleisches. Ihr Mann aber aß nicht mit ihr zusammen, sondern tafelte mit seinen Brüdern und anderen Verwandten. Maria gab daraufhin in einer Bemerkung ihrem Bedauern darüber Ausdruck. Diese Bemerkung wurde von einem böswilligen Menschen ihrem Mann in entstellter Form überbracht, der darüber in große Wut geriet. Er hielt sich jedoch vorerst noch zurück wegen der Personen, die anwesend waren. In der folgenden Nacht jedoch griff er sich eine Peitsche und schlich in Marias Schlafgemach. Dort, im Schein des Lichts, das vor einer Marienikone brannte, sah er "die Selige auf dem Bett liegen und einen Säugling in ihren Armen halten". ${ }^{25}$ Er packte sie bei den Haaren und begann auf sie einzuschlagen, bis eines der Kinder hinauslaufen und Hilfe holen konnte. Den Helfern gelang es, Nikephoros von Maria zu trennen, so daß diese davonlaufen konnte. Dabei stürzte sie jedoch und zog sich eine Kopfverletzung zu. Aufgrund des Zusammenspiels der drei Gründe, nämlich ihrer Krankheit, ihrer Traurigkeit und der Verletzung, wurde sie krank und bettlägerig. Maria überzeugte nun noch ihren „Verfolger“, nämlich ihren Mann Nikephoros, verfügte milde Gaben

23 Wir haben hier eine der ganz raren Darstellungen häuslicher Gewalt in Byzanz, die durchaus nicht wirklichkeitsfern wirkt. Vgl. dazu Pratsch, Maria 567-569.

24 Vita Mariae iun. (BHG 1164) cap. 7-10, p. 695B-696E.

25 Das Marienbild (,Jungfrau mit Kind") findet sich hier, eingeleitet durch die vorherige Erwähnung der Marienikone, natürlich nicht zufällig, sondern unterstützt und dramatisiert gleichzeitig die Handlung: Nikephoros richtet seine teuflische Wut gegen „eine zweite Maria"! 
an die Armen und verstarb schließlich mit den Worten: „Siehe, der Himmel öffnet sich, und ich sehe unsagbares Licht und in der Höhe einen Kranz." Beispiele für diesen Topos finden sich im betrachteten Zeitraum nicht allzu häufig, da wirkliche Martyrien nur noch selten vorkamen ${ }^{26}$.

\section{$\$ 2$. Bekenntnis (bomologia- confessio)}

In der Vita des Nikolaos Studites (BHG 1365) findet sich eine ausgedehnte Schilderung des Bekenntnisses zum rechten Glauben ${ }^{27}$, das Nikolaos, gemeinsam mit seinem geistlichen Vater, Theodoros Studites, vor dem ikonoklastischen Kaiser Leon $\mathrm{V}$. und dessen Schergen ablegte ${ }^{28}$ : Er bekannte sich zur Rechtmäßigkeit der Ikonenverehrung und wurde daraufhin gemeinsam mit Theodoros verbannt. Anschließend mußten Nikolaos und Theodoros fast fünf Jahre in der Verbannung zubringen. In dieser Zeit wurden sie zweimal verlegt, einmal von der Festung Metopa in Bithynien nach Boneta in Zentralkleinasien und später von dort nach Smyrna, und mehrfach von kaiserlichen Beauftragten aufgesucht und ausgepeitscht. Jede einzelne dieser Züchtigungen ist als ein Bekenntnis dargestellt ${ }^{29}$ : Nikolaos und Theodoros versäumen keine Gelegenheit, sich zum rechten Glauben (also zur Rechtmäßigkeit der Ikonenverehrung) zu bekennen, und nehmen dafür schwerste körperliche Strafen in Kauf. In der Zusammenschau der längeren Darstellung ergibt sich ein großes, weil mehrmaliges und wiederholtes, Bekenntnis der beiden. Interessant an der Darstellung dieser Vita ist aber auch, wie das Bekenntnis dort in die Nähe des Martyriums gerückt wird: Anläßlich einer Züchtigung des Nikolaos heißt es beispielsweise, daß „das Blut des

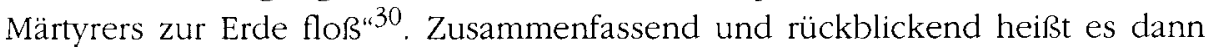
zum Bekenntnis des Nikolaos und des Theodoros, „wie sie ihre Tugend in der Glut der Folter bewiesen, so zeigten sie auch, daß sie den Tod selbst auf sich

26 Weitere Beispiele: (echtes Martyrium) Vita Eliae iun. Damasc. (BHG 578-579) cap. 11-20, p. 49,6 - 55,11; (Amputation der rechten Hand) Vita Ioannis Damasceni (BHG 884) cap. 17, col. 456B-D; ferner Niketas Monomachos, vgl. Gamillscheg, Gegebenheiten 9 Anm. 51; Nikolaos en Bunaine, vgl. Gamillscheg, Gegebenheiten 17f.; zu weiteren Beispielen, auch aus Passiones und Synaxarnotizen, vgl. zusammenfassend C. Ludwig, in: PMBZ, Prolegomena 107-117. Martyrium bzw. Bekenntnis der Theodoros und Theophanes Graptos in der Vita Mich. Syncell (BHG 1296) cap. 19-23, p. 82-96, vgl. dazu Sode, Viten 227-234.

27 Zum Bekenntnis in Heiligenviten vgl. auch Cunningham, Life 27f,; zur ó

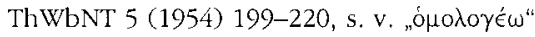

28 Vita Nicolai Studitae (BHG 1365) col, 880C-889C; zu den historischen Einzelheiten vgl, Pratsch, Theodoros 203-261, bes. 247-261.

29 Zu diesen Züchtigungen vgl. Pratsch, Theodoros 250-256.

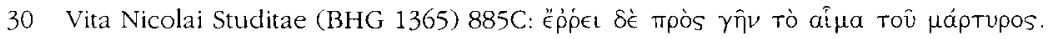


nehmen würden“31. Das Bekenntnis wird hier also gewissermaßen ein unvollendetes bzw. unvollkommenes Martyrium dargestellt.

In der Darstellung der Vita des Euthymios von Sardeis (BHG 2145) wird der Heilige in die Verbannung nach Pantellaria geschickt, weil er eine junge Frau auf deren Wunsch hin zur Nonne geschoren und geweiht hatte, auf die der Kaiser (Nikephoros I.) angeblich ein Auge geworfen hatte. Der Aufenthalt des Euthymios in Pantellaria wird nun als ein Bekenntnis des Heiligen für Christus gewertet. Euthymios wird mit den Aposteln Petros und Andreas sowie mit Ioannes Chrysostomos verglichen und seine Verbannung als "todesgleiches Exil" ( $T \grave{\eta} v$

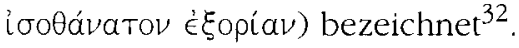

Auch Ioannes Psichaites legt nach der Darstellung seiner Vita (BHG 896) ein ausführliches und unmißverständliches Bekenntnis für die Ikonenverehrung $\mathrm{ab}^{33}$. Die elaborierte Darstellung dieser Vita enthält verschiedene Elemente eines Märtyrerprozesses: Ioannes Grammatikos saß als Vertreter des häretischen Klerus gemeinsam mit seinen Anhängern über Ioannes vom Psichakloster zu

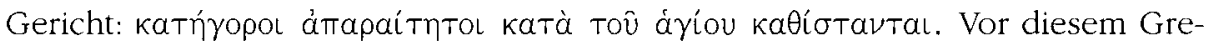
mium entlarvte Ioannes das Verbot der Ikonenverehrung als Neuerung und Hä-

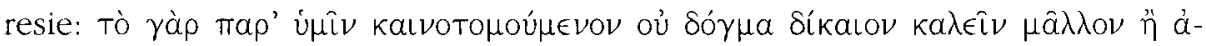
vó $\eta$ $\mu$ a. Der Heilige wurde vor Ioannes Grammatikos und dem Stadteparchen von Konstantinopel verhört wie einst Jesus vor Hannas und Pontius Pilatus. Ioannes konnte freilich sämtliche gegen ihn vorgebrachten Anschuldigungen und Verleumdungen grüdlich widerlegen. Er wurde daraufhin einem Henkers-

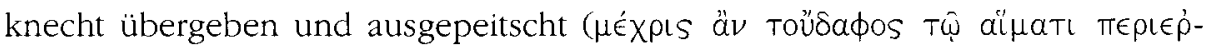
$\hat{\rho} \alpha \dot{v} \theta \eta)$. Diese Mißhandlungen zogen sich über sieben Tage hin. Anschließend wurde er vor den Kaiser (Leon V.) selbst geführt, bekannte sich erneut zu seinem Dogma und wurde wiederum mit Auspeitschung bestraft und in den Kerker geworfen. Später versucht ein weiteres Mal Ioannes Grammatikos dem Heiligen mit angeblichen "magischen" Mitteln beizukommen ${ }^{34}$, was ebenfalls mißlingt. Ioannes wird dann in die Verbannung geschickt.

In der Darstellung der Vita Platonis (BHG 1553) bekennt Platon sich vor dem Kaiser (Konstantin VI.) zum rechten Glauben, der in diesem Fall darin besteht, die zweite Ehe des Kaisers als unrechtmäßig abzulehnen ${ }^{35}$ : Der Hirte wurde aus der Herde entfernt und seine Schafe zerstreut. Von starker Hand

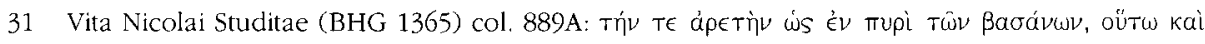

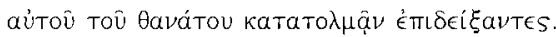

32 Vita Euthymii Sard. (BHG 2145) cap. 6, p. 27-29. Die Vita dieses Hl. bietet noch zahlreiche an dere Bekenntnisse, s. dazu noch unten unter den weiteren Beispielen.

33 Vita Ioannis Psichaïtae (BHG 896) cap. 7, p. 114-118.

34 S. dazu bereits oben Kap. 9: „Gegenspieler“, vgl auch Pratsch, Gegenspieler 72-89, hier 82f

35 Vitá Platonis (BHG 1553) cap. 27-28, col. 829C - 832B. Vgl. dazu Pratsch, Theodoros 107-110. 
wurde er vor den Kaiser geführt, dem er von Angesicht zu Angesicht gegenüberstand wie Johannes der Täufer dem Herodes. Er aber ließ sich nicht einschüchtern, sondern sprach unerschrocken vor dem Kaiser und bekannte sich

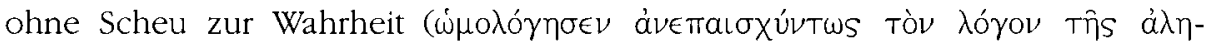
$\theta \in i a s)$. Und wie der Täufer zu Herodes gesprochen hatte, so sprach auch der Nachahmer des Täufers zu dem Gleichgearteten des Herodes (sc. dem Kaiser). Wörtlich heißt es nun ${ }^{36}$ : „Und es wurde ihm nun keineswegs das Haupt abgeschlagen, weil der Kaiser den, der durch seine Gesinnung zum Kämpfer für Christus geworden war, nicht noch zum Märtyrer machen wollte, wie er vorausschauend erkannte. Als Bekenner Christi aber zeigte er ihn, auch ohne es zu wollen, auf."

Theodoros Studites, der Neffe Platons, war nicht nur in die eben genannte Auseinandersetzung, sondern gleich in eine ganze Reihe von Auseinandersetzungen verwickelt und wurde insgesamt dreimal mit Verbannung bestraft ${ }^{37}$. Infolgedessen finden sich in der Vita des Theodoros - der von seinen Mönchen

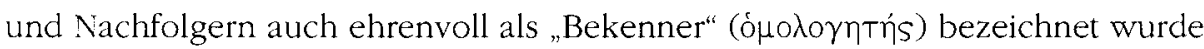
- eine ganze Reihe von Bekenntnisszenen. Ein besonders umfangreiches und mit dem Motiv der "Überzeugung der Verfolger“ untermischtes Bekenntnis soll hier beispielhaft vorgeführt werden ${ }^{38}$ : Nach Darstellung der Vita wurde Theodoros an seinem Verbannungsort Boneta im Thema Anatolikon von einem Kleriker aus dem Thema Thrakesion besucht. Theodoros ermahnte diesen zur Orthodoxie (sc. zur Ikonenverehrung). Nachdem er in seine Heimat zurückgekehrt war, vertraute sich der Kleriker einem anderen Kleriker an. Beide sagten sich dann von ihrem Bischof los. Der Bischof beschwerte sich über die beiden Kleriker beim Strategos des Themas Thrakesion namens Orabe ('Opaß́́), der daraufhin zum einen den Strategos des Themas Anatolikon, zum anderen den Herrscher über die Aktivitäten des Theodoros informierte. Zum einen befahl dann der Strategos des Anatolikon einem seiner Würdenträger ( namens Theophanes, Theodoros mit fünfzig Peitschenhieben zu bestrafen. Der Beauftragte brachte es jedoch angesichts des ausgemergelten Körpers nicht übers Herz, die Bestrafung durchzuführen, sondern fiel auf die Knie und küßte dem Heiligen die Füße. Zum anderen schickte auch der Kaiser einen Boten

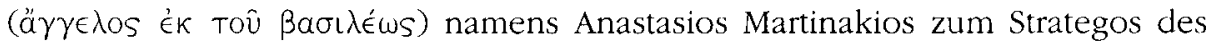
Anatolikon, der die Sache überprüfte, dabei die unterlassene Bestrafung bemerkte und Theodoros eigenhändig mit 100 schweren Hieben bestrafte. An-

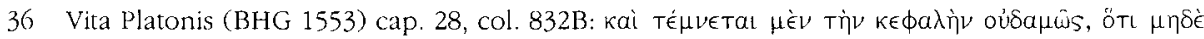

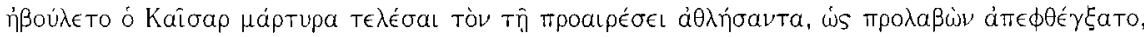
ó

37 Vgl. dazu Pratsch, Theodoros passim.

38 Vita Theod. Stud. (BHG 1754) cap. 39-40, col. 289D - 293A. Vgl. dazu Pratsch, Theodoros 255f 
schließend sperrte Anastasios Theodoros zusammen mit dessen Jünger Nikolaos

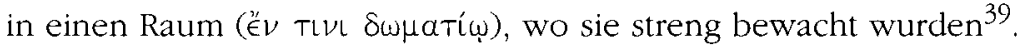

\section{$\S 3$. Askese}

In der Darstellung der Vita des Georgios von Amastris (BHG 668) heißt es, nachdem der Heilige soeben in das Bonyssakloster eingetreten war ${ }^{40}$ : „Und von nun an gehörte der Wunderbare jener bewunderungswürdigen Gemeinschaft an, die darum wetteiferte, einen körperlosen Zustand im Fleische zu erlangen. Und er nahm die Kämpfe der Askese an und wies jede Annehmlichkeit des ganzen unruhigen Lebens weit von sich. Er zog seinen Sinn nicht herab auf irgendeines der zum Leben notwendigen Dinge, sondern legte seinen ganzen Eifer in den Erwerb der ewigen Güter - wie er zu Gerechtigkeit und Maß gelangen könnte, wie er Klugheit und Tapferkeit erreichen könnte, wie er all die übrigen Tugenden erwerben könnte, die natürlicherweise aus diesen Kardinaltugenden hervorgehen." Die Askese ist hier noch mit anderen Tugenden ${ }^{41}$ untermischt.

In der Vita Konstantins des Juden (BHG 370) heißt es an einer Stelle nur ${ }^{42}$ : „Doch jenen (sc. Konstantin) nun nahm der Olymp auf zu vielen Kämpfen der Tugend und zum Fasten, das beinahe zu seiner völligen Abmagerung führte

39 Weitere Beispiele: Vita Euthymii Sard. (BHG 2145) cap. 8-10, p. 31-37 (Bekenntnis vor Leon V. zu Ikonenverehrung); cap. 11-12, p. 37-39 (Bekenntnis vor Michael II.); cap. 13-14, p. 39-43 (Bekenntnis vor Theophilos); Vita Ignatii (BHG 817) col. 521A-B; 529C-532A; Vita Antonii iun. (BHG 142) cap. 32, p. 209,22 - 210,23; Vita Eliae iun. (BHG 580) cap. 13, p. 18-20; Vita Theod. Stud. (BHG 1754) cap. 16, col. 253C-D (vor dem Domestikos der Scholen und dem Strategos des Opsikion, vgl. Pratsch, Theodoros 107-110); cap. 25-27, col. 265B - 269B (vor Archonten und Synode, vgl. Pratsch, Theodoros 167-170); Vita Methodii (BHG 1278) cap. 5, col. 1248C (Bekenntnis vor Michael II); Vita Greg. Agrig. (BHG 707) cap. 57-85, p. 213-246 (vor Synode, unter Beteiligung von Kaiser und Patriarch); Vita Theoph. conf. (BHG 1787z) cap. 45-46, p. 28,8 - 30,14 (vor Leon V.); Vita Ioannis Damasceni (BHG 884) cap. 14, col. 449B-453A (schriftlich, gegenüber Leon III.); Vita Procopii Decapol. (BHG 1583) cap. 13-19, p. 317-319. Bekenntnisse anderer Personen als der Vitenhelden: Vita Stephani iun. (BHG 1666) cap. 35-36, p. 134-136 (Bekenntnis der Nonne Anna); Vita Mich. Syncell. (BHG 1296) cap. 19-23, p. 82-96 (Martyrium bzw. Bekenntnis des Theodoros und Theophanes Graptos), vgl. dazu Sode, Viten 227-234; Bekenntnis in Synaxarnotiz: Synax. Cpl. 115,14 - 116,15; Men. Basilii 93B-C (Niketas Monomachos, cf. PMBZ: \#5424).

40 Vita Georg. Amastr. (BHG 668) cap. 13, p. 22,9-23,3.

41 Zu den "Tugenden" s. bereits oben Kap. 11. Zur Askese vgl. auch Lietzmann, Alte Kirche IV 116-125 [1108-1117]; 154-194 [1146-1186].

42 Vita Constantini Iudaei (BHG 370) cap. 23, p. 634D. Askese kommt in dieser Vita auch noch an anderer Stelle, mehrfach in die Narratio eingestreut, vor. 
durch das Übermaß des Nahrungsentzugs. Ein so bewundernswertes Leben führte er."

In der Vita des Nikon „Metanoeite“ (BHG 1366-67) ist die Darstellung wesentlich ausführlicher. Nikon übte sich vor allem im Fasten ( $\nu \eta \sigma T \in i a)$ und im

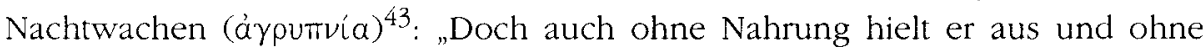
Speise. Jede Art von Essen lehnte er ab, so daß er nur einmal am Anfang der Woche sich der Speise besann und ganz wenig zu sich nahm und nichts, was zum Genuß geeignet war. Er kämpfte nämlich sehr gegen alles, was den Magen erfreute. Ständige Schmerzen und Entbehrungen und alle anderen Dinge, die dem Fleische Pein bereiten, nahm er bereitwillig auf sich. Nur ein kleines Stück Brot war sein Mahl, und zum Brot gab es Salz. Und das Erstaunlichste dabei war, daß er in jeder Hinsicht unerfahren war und keinen Lehrer oder Führer in diesen Dingen hatte, sondern von Hause aus und aus sich selbst von Anfang an, sozusagen von der Startlinie weg sich mitten in die Kämpfe begab, und er hatte Hände, die geeignet waren zur Schlacht, und Finger, die geschaffen waren zum Krieg ${ }^{44}$. Im Laufe der Zeit, als er diese derartigen Anstrengungen beherrschte, und seine Seele an eine derartige, sehr harte Lebensführung gewohnt erschien, nahm er einmal in der Woche an den göttlichen Mysterien teil, und nach der Teilnahme daran aß er ein kleines Stück Gerstenbrot, das so voller Schmutz und eingetrocknet war, daß es nicht einmal mehr durch seinen Geruch an Brot erinnerte. Sein Getränk war Wasser, das er maßvoll und selten zu sich nahm. Und als sein Gesicht nun schon ganz eingefallen war und alle Glieder seines Körpers ausgezehrt, verbrachte er weiterhin die Tage ohne Nahrung und ertrug die Last des Notwendigen und hielt in außergewöhnlicher Weise die maßlose Pein aus. Jede Nacht verbrachte er ohne Schlaf, denn die dringlichere Aufgabe war ihm das tränenreiche Gebet und die ständige Vorbereitung auf den mühevollen Kampf gegen den Schlaf. Auf diesem Gebiet wetteiferte er mit dem heiligen Arsenios. Wie jener, so konnte nämlich auch er, wenn er einmal durch die Not des Körpers ein klein wenig Schlaf, und dies nur ein Hauch und kaum der Rede wert, gekostet hatte, sofort umgehend wieder aufspringen und die Worte Davids ${ }^{45}$ singen und sagen: 'Ich komme in der Frühe und schreie' usw." Der Topos der Askese kehrt in den anschließenden Kapiteln der Vita noch mehrfach wieder (capp. 6-11 u. ö.).

Etwas anders geartet ist die Darstellung der Askese des David in der Vita der Gebrüder David, Symeon und Georgios (BHG 494), die sich etwa wie folgt zu-

43 Vita Niconis (BHG 1366-67) cap. 5,41-72, p. 42-46.

44 Zur militärischen Terminologie (Metaphorik) in der Darstellung der Askese des HI. vgl. auch Scharff, Kämpfe 33-36.

45 P. 118.147 
sammenfassen läßt ${ }^{46}$ : David ließ sich am Berg Ida, gegenüber von Lesbos auf dem kleinasiatischen Festland, nieder. Dort lebte er dann 30 Jahre in der verlassenen Wildnis und in den Bergen. Er aß wildwachsende Pflanzen und Früchte und trank Quellwasser. Er ließ sein Haar lang wachsen, das bald seine einzige Bekleidung war $^{47}$. Sein Zuhause war das Unterholz, er schlief in Felsnischen und Höhlen ${ }^{48}$.

In der Darstellung der Vita des Michael Synkellos (BHG 1296) ist an einer Stelle das Fasten bzw, die Askese klar in den Zusammenhang mit dem Martyrium bzw. Bekenntnis gestellt. Der Heilige und seine Jünger befanden sich zu diesem Zeitpunkt, nach ihrem Bekenntnis für den rechten Glauben, in kaiserlicher Haft, lehnten aber die ihnen vom Kaiser angebotenen Speisen strikt ab, übten also zusätzlich und freiwillig Askese ${ }^{49}$ : „Viele Tage vergingen, und die Heiligen verbrachten sie im Fasten. Sie wollten nämlich nichts Eßbares von den Dienern des erbarmungslosen Tyrannen annehmen, weil diese ja Häretiker waren und Christus haßten, wenngleich ihnen der Kaiser viele Dinge geschickt hatte, Datteln und getrocknete Feigen und vieles andere, von dem er wußte, daß es als Speise für Asketen geeignet war. Sie nahmen diese Dinge nicht an, sondern begegneten ihm mit dem Wort des heiligen Psalmisten David, das da lautet $^{50}$ : 'das Öl eines Sünders soll mein Haupt nicht salben'. Sie zogen es vor, eher Hungers zu sterben, als auch nur etwas von denen zu kosten."

46 Vita Davidis, Symeonis et Georgii (BHG 494) cap. 5, p. 215,14f.

47 Vgl. D. Abrahamse, in: Byzantine Defenders 156 Anm. 67; zu den Vorbildern dieser strengen Form der Askese vgl. Caner, Monks 50-53.

48 Weitere Beispiele: Vita Davidis, Symeonis et Georgii (BHG 494) cap. 7,16-21, p. 217; Vita Mich. Syncell. (BHG 1296) cap. 4, p. 52,1-14; Vita Ioannis Psichaïtae (BHG 896) cap. 4, p. 110; Vita Euthymii iun. (BHG 655) cap. 17, p. 182f. (lebt 40 Tage wie ein Tier und ernährt sich von Gras). - Vgl, auch Müller, Vita 589-591.

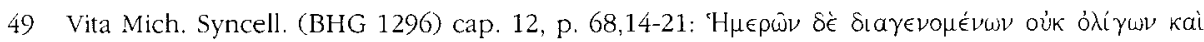

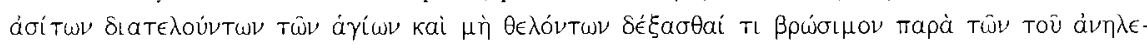

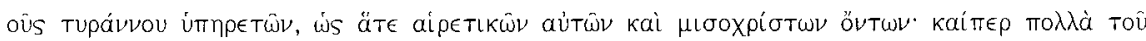

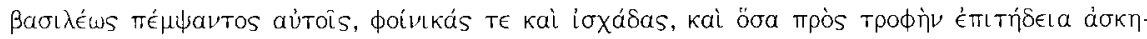

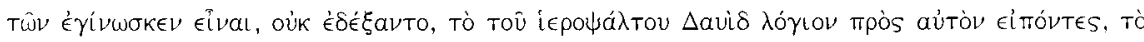

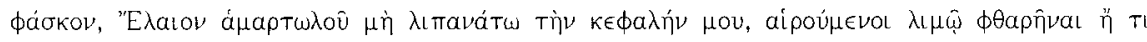

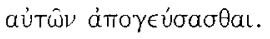

50 Ps 140.5 (LXX).

51 Weitere Beispiele: Vita Stephani iun. (BHG 1666) cap. 57, p. 160; Vita Theod. Cyth. (BHG 2430) p. 286,154-179; 288, 214-234; Vita Petri Atroënsis (BHG 2364) cap. 37,31-37, p. 147 u. ö; Vita Lazari Galesiotae (BHG 979) cap. 17, p. 514f. (Speis und Trank); cap. 35, p. 520 (Kleidung, Eisen Schlaf). 


\section{$\S 4$. Bestechungsversuche}

In diesen Kontext läßt sich auch das Motiv der versuchten Bestechung einordnen: Ein Herrscher oder anderer Verfolger bzw. Gegenspieler ${ }^{52}$ des Heiligen versucht im Zuge des angedeuteten Glaubensprozesses, diesen durch Versprechungen umzustimmen. Der Heilige erweist sich freilich als standhaft und lehnt alle Bestechungsversuche ab, denn nur so kann er sich als Märtyrer bzw. Bekenner erweisen ${ }^{53}$.

In der Vita des Patriarchen Methodios (BHG 1278) wird diese Art von Bestechungsversuch durch Kaiser Theophilos wie folgt dargestellt ${ }^{54}$ : „Aber nun sah jene hinterhältige Schlange (sc. der Kaiser Theophilos) ein, daß der Soldat Christi (sc. Methodios) nicht den Charakter hatte, sich der Folter zu beugen, da er eine standhafte Seele hatte und Kraft, und verlegte sich genau auf das Gegenteil und versuchte, diesen durch Schmeichelei und Ehrungen auf seine Seite zu ziehen. Und nachdem er ihn zu sich gerufen hatte, sprach er ihm milde und freundlich zu und bat ihn, ihm Fragen hinsichtlich der Bibel zu beantworten, und versicherte, ihm wohlgesonnen zu sein. Schließlich ordnete er an, daß er zusammen mit seinen treuen Schülern innerhalb des Palastes wohnen solle."

Auch in der Vita des Theodoros Studites (BHG 1754) findet sich der Versuch der Bestechung. Kaiser Konstantin VI. habe gehofft, Theodoros und Platon, den Onkel und geistlichen Vater des Theodoros, zur Anerkennung seiner zweiten Ehe bewegen zu können, weil ja seine zweite Frau Theodote deren Verwandte war $^{55}$ : „Daher ermutigte er sie (sc. Theodote) auch, ihnen (sc. Theodoros und Platon) Gold zu schicken mit ihrer geziemenden Verehrung." Die heiligen Väter ließen sich davon freilich nicht umstimmen und blieben bei ihrer ablehnenden Haltung, so daß es zu ihrer Bestrafung kam ${ }^{56}$.

52 Vgl. daher auch oben Kap. 9: „Gegenspieler“, S. 170-183, sowie Pratsch, Gegenspieler 72-89.

53 Vgl auch Scheibelreiter, Gegner 75: "der Heilige, der schroff die Wohltat des Bösen ablehnt".

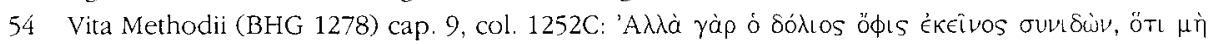

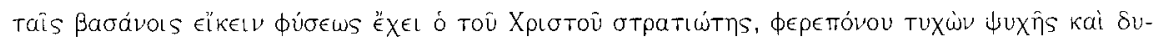

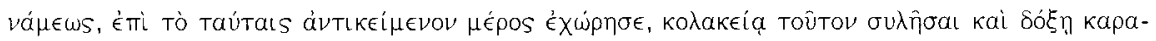

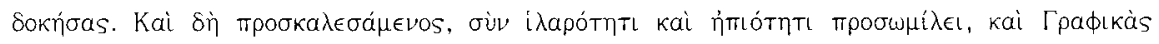

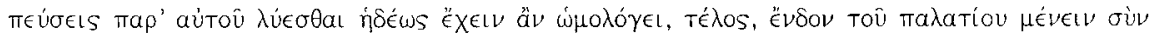

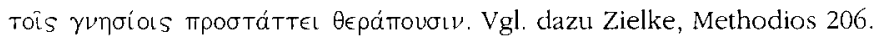

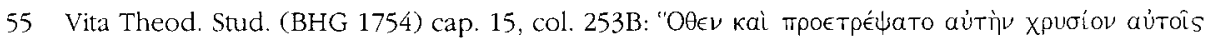

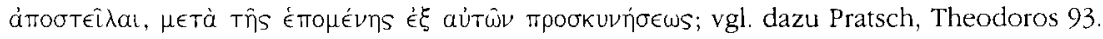
Weiteres Beispiel: Vita Procopii Decapol. (BHG 1583) cap. 15, p. 317. 


\section{$\$ 5$. Bestrafung}

Ein integraler Bestandteil des Martyriums und ein optionaler Bestandteil des Bekenntnisses ist die Bestrafung des Heiligen. Sie gewinnt insofern Eigenständigkeit als Topos, da sie auch isoliert, also nicht integriert in ein Martyrium oder im Anschluß an ein Bekenntnis, vorkommen kann. Jedwede Art von Bestrafung des Heiligen steht dann pars pro toto für Bekenntnis bzw. Martyrium desselben. Es lassen sich vier Formen der Bestrafung unterscheiden: Absetzung (A), Züchtigung (B), Haft (C) und Verbannung (D), die auch miteinander verbunden, aufeinander folgend oder einander abwechselnd, dargestellt werden können.

\section{A. Absetzung}

In der Darstellung der Viten ist die Absetzung im Zusammenhang der verschiedenen Bestrafungen häufig nur impliziert und seltener besonders ausgearbeitet. Zum einen wollte man wohl diese kirchenrechtliche Bestrafung des Heiligen bisweilen weglassen, zum anderen war es für die Rezipienten ohnehin klar, daß der strafrechtlichen Verfolgung und Bestrafung durch Züchtigung, Haft und/ oder Verbannung die kirchenrechtliche Absetzung vorausgegangen sein mußte. In einigen Viten findet sich dennoch die Absetzung zumindest angedeutet. Wenn es etwa in der Vita des Theodoros Studites (BHG 1754) heißt, die kaiserli-

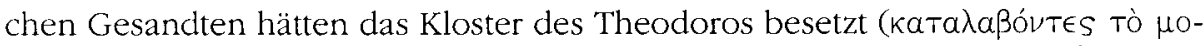
vaotńplov), so ist klar, daß sie ihn damit seines Amtes enthoben hatten ${ }^{57}$.

In der Vita Symeons, des neuen Theologen (BHG 1692), ist die Absetzung Symeons an einer Stelle in dem einen Satz impliziert ${ }^{58}$ : „Und wiederum wird mein Symeon von dem Kloster in das Gericht geführt." Im Anschluß daran wurde Symeon mit Verbannung bestraft. Es ist also klar, daß er abgesetzt worden war.

In der Vita des Nikolaos Studites (BHG 1365) wird dessen Absetzung als Hegumenos des Studiosklosters durch Kaiser Michael III. und den Kaisar Bardas im Jahre 858 dargestellt. Nikolaos hatte nach der Absetzung des Patriarchen Ignatios aus Protest sein Hauptkloster bereits verlassen und hielt sich in einem Katagogion des Studiosklosters außerhalb Konstantinopels, in Prainetos in Bithynien auf. Dort suchten ihn die Herrscher auf, um ihn zum Einlenken zu bewegen; als dies nichts fruchtete, geschah folgendes ${ }^{59}$ : „Sie (sc. Kaiser Michael III. und der Kaisar Bardas) schickten nun hinterher einen Mann zu dem Heiligen

57 Vita Theod. Stud. (BHG 1754) cap. 16, col, 253C

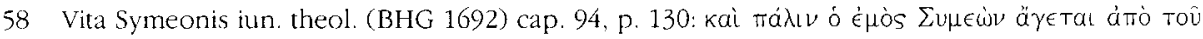

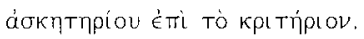


und eröffneten diesem: 'Es ist nicht nötig, daß du dich in einem der Katagogia deines Klosters aufhältst!' Und offenbar zur Abwehr (sc. eines möglichen Widerspruchs 0 . ä.) weihten sie sogleich an seiner Statt einen Abt, Achillas nun war sein Name, der in jeder Beziehung tüchtig in seiner Art war."

Die Absetzungen des Theodoros Studites als Abt des Studiosklosters, die in dessen Vita (BHG 1754) geschildert werden, wurde anderenorts ausführlich behandelt ${ }^{60}$.

\section{B. Züchtigung}

In der Vita des Theodoros Studites (BHG 1754) taucht auch das Motiv der Züchtigung wiederholt auf ${ }^{61}$. Die erste dieser Bestrafungen fand wohl im Jahre 796 statt, dazu heißt es in der Vita ${ }^{62}$, „Und er (sc. der Kaiser) schickte nun den Domestikos der Scholen und zusammen mit diesem auch den Strategos des Opsikion, damit diese die Mißhandlung der Heiligen ausführten. Diese besetzten das Kloster und züchtigten mit Peitschenhieben bis zur Sättigung den, der wegen Christus ohnehin fortwährend danach dürstete, und drei weitere der führenden Brüder."

Auch der Patriarch Methodios wurde nach der Darstellung seiner Vita (BHG 1278) mehrmals mit Peitschenhieben gezüchtigt. Zunächst kam er mit einem Lehrschreiben des Papstes zu Kaiser Michael II. nach Konstantinopel, um diesen zur Orthodoxie (sc. zur Annahme der Ikonenverehrung) zu bekehren ${ }^{63}$ : „Der (sc. Kaiser) aber nahm zwar die Bände entgegen, die er verächtlich als ein Spinnennetz bezeichnete, ihn (sc. Methodios) aber, der die Dinge des orthodoxen Glaubens deutlich und freimütig verkündete, nannte er einen Urheber von Unruhe und Ärgernissen und überließ ihn 700 Peitschenhieben ${ }^{64}$. Und so wurde er,

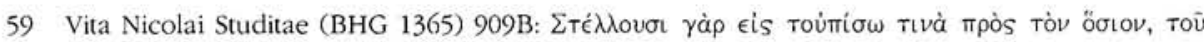

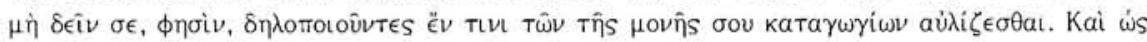

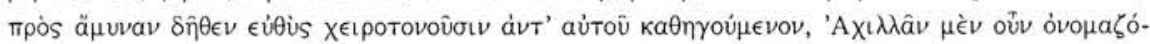

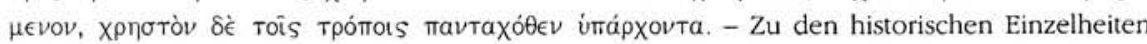
vgl. PMBZ: $\# 5576$ (Nikolaos Studites).

60 Vgl. Pratsch, Theodoros 157-173 (Absetzung, Haft, Verbannung a. 809); 231-234 (Absetzung, Verbannung a. 815); 107-110 (Absetzung und Haft des Platon, Hegumenos des Sakkudionklosters, auch nach der Vita Platonis [BHG 1553], Verbannung a. 797).

61 Vgl. Pratsch, Theodoros 250f. 255f. 257f. Einige Beispiele sind oben bereits gestreift worden.

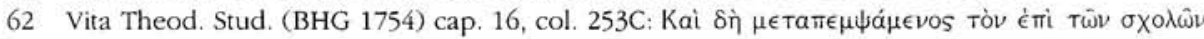

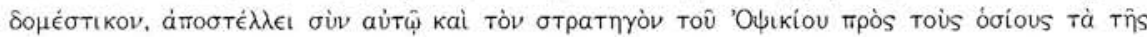

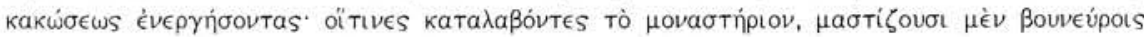

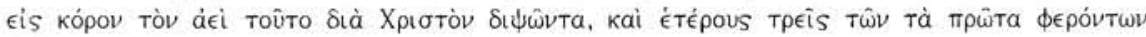

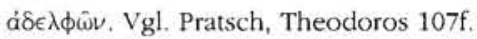


halbtot und kaum noch atmend, zunächst in ein Gefängnis und dann in ein Grab auf der Insel des Apostels Andreas (sc. Hagios Andreas) eingeschlossen." Später sei Methodios dann auch von Kaiser Theophilos mit Züchtigung bestraft worden, weil er den Kaiser in einem Disput über die Rechtmäßigkeit der Ikonenverehrung vollkommen widerlegt habe ${ }^{65}$ : „Und der (sc. Kaiser Theophilos) nun, der die Schmach der Erwiderung nicht ertrug, verwandelte seine Mahnung in Zorn, und nachdem er angeordnet hatte, daß ihm die Kleider ausgezogen würden, verabreichte er ihm über 600 Peitschenhiebe auf seinen nackten Rükken und die Brust und befahl, den so Halbtoten und von allen Seiten Blutüberströmten durch ein Loch in ein unterirdisches Gewölbe des Palastes zu werfen." 66

\section{Haft}

In der Vita Platonis (BHG 1553) folgt nach dem Bekenntnis des Heiligen vor dem Kaiser (Konstantin VI.) dessen Bestrafung durch Inhaftierung ${ }^{67}$ : ,..., (sc. der Kaiser) spertte den Schatz der Wahrheit in irgendeine Hütte, sicherte sie mit vielen Schlössern und befahl, daß ihm durch ein Loch die Nahrung gereicht werde, damit der, der von Gott gesehen wurde, von keinem der anderen gesehen werden konnte."

Auch in der Vita des Michael Synkellos (BHG 1296) werden im Anschluß an ein Bekenntnis Züchtigung und Inhaftierung dargestellt ${ }^{68}$ : „Nachdem diese

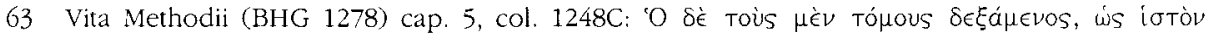

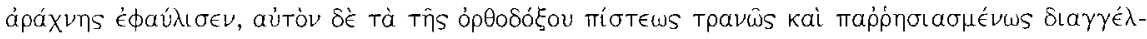

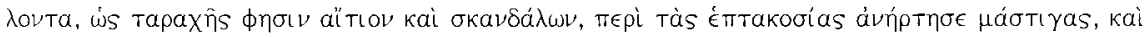

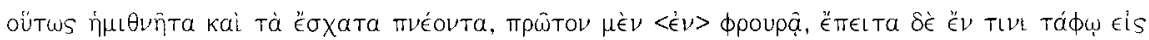

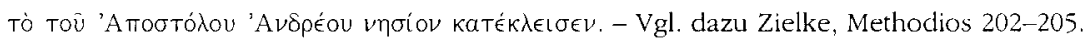

64 Zur unrealistischen Anzahl der Hiebe vgl. Zielke, Methodios 202 Anm. 81.

65 Vita Methodii (BHG 1278) cap. 8, col. 1252A-B. - Vgl. dazu Zielke, Methodios 205f.

66 Weitere Beispiele: Vita Mich. Syncell. (BHG 1296) cap. 12, p. 68,1-4; Vita Theod. Stud. (BHG 1754) cap. 39-40, col. 292A-293B (vgl. Pratsch, Theodoros 255f); cap. 42, col 296A-C (vgl. Pratsch, Theodoros 257f.); Vita Procopii Decapol. (BHG 1583) cap. 19, p. 319.

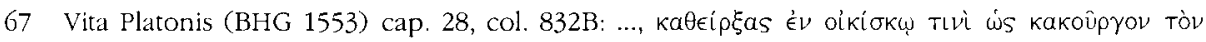

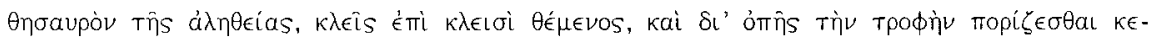

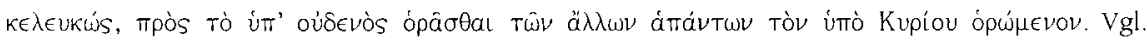
Pratsch, Theodoros $108 \mathrm{f}$.

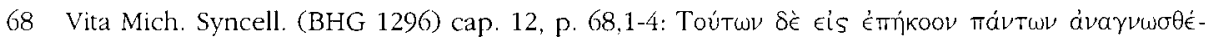

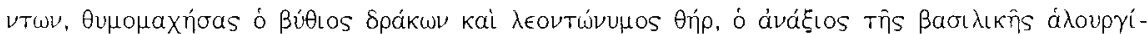

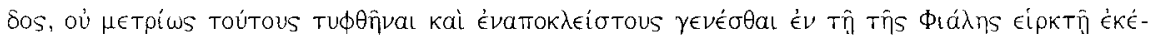

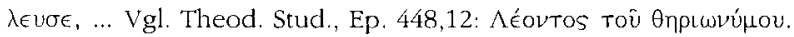


Worte vor aller Ohren laut verlesen worden waren, geriet der Drache aus der Tiefe, das löwennamige Untier (sc. Kaiser Leon V.), das des kaiserlichen Purpurs unwürdig war, in großen Zorn und befahl, daß diese (sc. Michael und sein Jünger $\left.{ }^{69}\right)$ schwer gezüchtigt und im Gefängnis der Phiale eingeschlossen würden."

In der Vita des Niketas von Medikion (BHG 1341) wird berichtet, wie Niketas von Kaiser Leon V. in Haft genommen wird ${ }^{70}$ : „Als der Kaiser sah, daß dieser (sc. Niketas) einen unwandelbaren Sinn besaß, übergab er ihn einem gewisssen Zacharias, dem Aufseher der kaiserlichen Besitztümer, des sogenannten Manganapalastes, um diesen dort eine Zeitlang für sich allein zu bewachen, bis er nach ihm sehen werde" 71 .

\section{Verbannung}

Überschneidungen mit der Darstellung der Haft weist die Darstellung der Verbannung auf, weil auch der Aufenthalt des Heiligen am Verbannungsort häufig als eine schwere Haft dargestellt wird ${ }^{72}$.

In der Vita des Theodoros Studites (BHG 1754) wird die erste Bestrafung des Heiligen mit Verbannung folgendermaßen dargestellt ${ }^{73}$ : „Sie (sc. die kaiserlichen Beauftragten) verbannten ihn nun zusammen mit zehn anderen der bedeutenderen Männer der Bruderschaft nach Thessalonike. Sie befahlen denen, die sie fortführten, diese eingeschlossen und sicher zu verwahren, nicht alle zusammen am selben Ort, sondern einen jeden an einem anderen Ort und in Abstand voneinander in verschiedenen Häusern, damit es nicht möglich wäre, daß der eine zum anderen ginge."

In der Vita des Niketas von Medikion (BHG 1341) läßt sich dazu vernehmen, daß, nachdem der Kaiser den Heiligen hatte im Manganapalast festsetzen lassen, folgendes geschah ${ }^{74}$ : „Danach verbannte ihn der Kaiser auf eine der In-

69 Theodoros und Theophanes Graptos, vgl. Sode, viten 213-215.

70 Vita Nicet. Medic. (BHG 1341) cap. 43, p. XXVI.

71 Weitere Beispiele: Vita Methodii (BHG 1278) cap. 5, col. 1248C; cap. 8, col. $1252 \mathrm{~B}$ (unter Theophilos, vgl. Zielke, Methodios 205f); vita Theoph. conf. (BHG 1787z) cap. 48-49, p. 30,30 31,29 .

72 Vgl. dazu die Überlegungen zu den tatsächlichen Haftbedingungen des Theodoros Studites an seinen Verbannungsorten und deren Darstellung in seinen Viten bei Pratsch, Theodoros 177. 248f. 251,253. 256f.

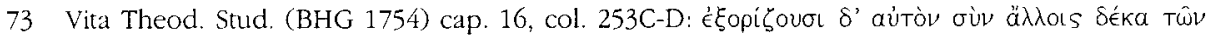

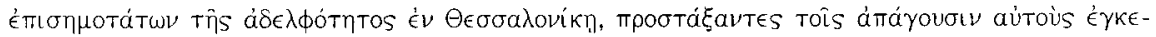

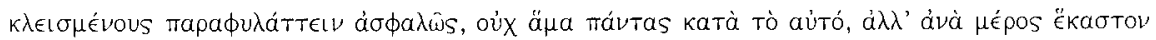

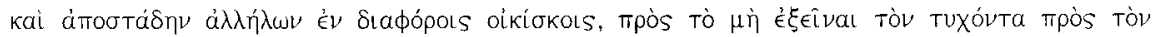

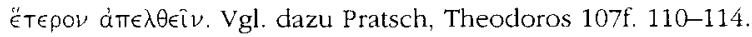


seln der Bucht, die Hagia Glykeria genannt wurde. Diese stand unter der Aufsicht eines gewissen Anthimos, eines Beschnittenen. Dieser war ein Gaukler, ein Tempelräuber, ein grober Klotz, ein Gottloser, war heimtückisch, anmaßend und unbarmherzig. Diesen nun machten die Gottlosen (sc. die Ikonoklasten) wegen seiner überragenden Schlechtigkeit zum Exarchos der dortigen Klöster. Solchen war nämlich damals die Herrschaft in die Hand gelegt, damit sie durch Gewalt alles sich gefügig machten. Kaïphas nannten diesen (sc. Anthimos) die Einheimischen wegen seiner großen Raserei, Tollheit und Hoffart. Dieser nun nahm den Heiligen in Empfang und, da er Gewalt über ihn hatte, peinigte er ihn gründlich. Er schloß ihn nun in eine enge und bedrückende Zelle, züchtigte ihn bis zum äußersten und ließ nicht einmal zu, daß dieser sich erholte. Er selbst trug den Schlüssel zum Gefängnis ständig bei sich und befahl, daß dem Heiligen die sehr kärgliche Speise durch ein Loch gereicht werde. Er hatte nämlich von den Gottlosen auch Versprechungen erhalten, daß ihm besondere Ehre zuteil würde, wenn er den Heiligen davon überzeugen könnte, sich ihnen anzuschlieBen. Deshalb peinigte er den Heiligen auch besonders heftig, weil der Unheilige glaubte, diesen überzeugen zu können." Die Bestrafung mit Verbannung geht hier nahtlos in eine Auseinandersetzung mit einer Gegenspielerfigur über ${ }^{75}$; die Haftbedingungen am Verbannungsort werden als besonders schwer und unangenehm gezeichnet.

Auch Patriarch Euthymios wurde in die Verbannung geschickt, weil er sich nach Aussage seiner Vita (BHG 651) einer zweiten Ehe des Kaisers Leon VI. widersetzte, indem er an den moralischen Qualitäten der Braut, Zoë Zautzina, Anstoß nahm ${ }^{76}$ : "Wenn du eine andere zur Frau nehmen willst, wird dich niemand hindern, doch es muß nicht diese sein, die des schlechten Benehmens überführt ist. Wenn dies nämlich geschieht, werden alle denken, daß tatsächlich alles wahr ist, was über sie geredet wird.' Und mit diesen Worten stand er auf und ging. Darüber war der Kaiser verärgert und rief nach dem Basileopator ${ }^{77}$ (sc.

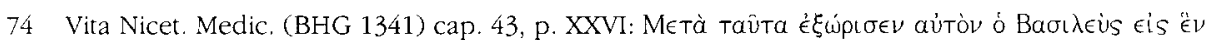

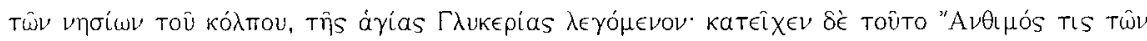

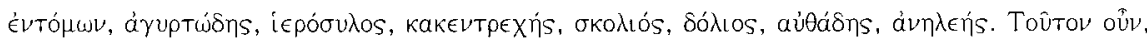

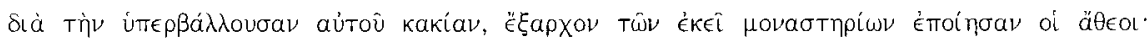

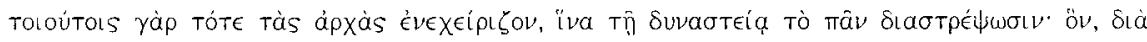

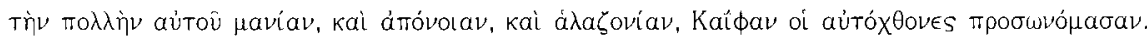

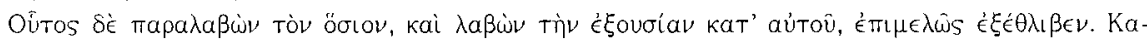

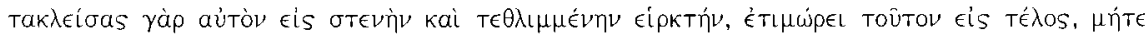

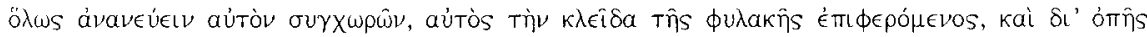

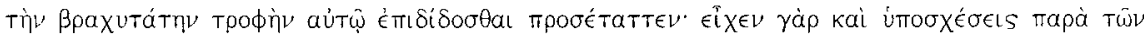

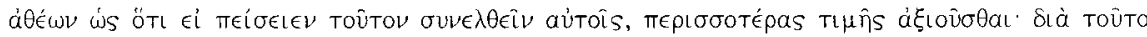

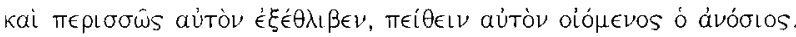

75 S. dazu oben Kap. 9: "Gegenspieler", S. 170-183, sowie Pratsch, Gegenspieler 72-89. 
Stylianos Zautzes, dem Vater der Zö̈). Nachdem er von diesem zu noch größerer Wut angestachelt worden war, befahl er, den Vater umgehend in das von seinem Vater Basileios erbaute Kloster des heiligen Diomedes zu verbannen, was auch sogleich geschah. “78

\section{\6. Überzeugung der Verfolger}

Aus dem Topos der Bestrafung heraus konnte ein weiteres Motiv entstehen, nämlich die Überzeugung der Verfolger: Durch die Strahlkraft seiner Heiligkeit überzeugt der Heilige seine Peiniger vom rechten Glauben. Dies kann die Bestrafung völlig abwenden, wird aber häufiger während oder erst nach bereits vollzogener Bestrafung dargestellt, nachdem der Heilige also bereits ein Opfer für Gott vollbracht hat ${ }^{79}$. Auch dieser Topos ist bereits der urchristlichen Überlieferung bekannt ${ }^{80}$.

Das Motiv findet sich etwa in der Vita (BHG 896) des Ioannes Psichaites. Nachdem Ioannes sieben Tage lang von einem Schergen bis aufs Blut ausgepeitscht worden war, richtete er folgende Worte an seinen Peiniger ${ }^{81}$ : "Ich will dir dankbar sein, sagte der Tapfere, wenn du mich jeden Tag der Schläge für würdig erachtest. Sie sind mir nämlich ein Labsal und keine Strafe!' Der Unmensch nun war niedergeschlagen von dem übermenschlichen Widerstand des Gerechten und befahl, daß dieser sicher im Gefängnis verwahrt werde." In die-

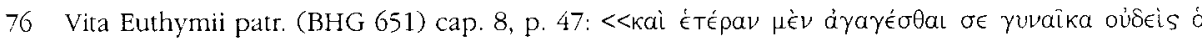

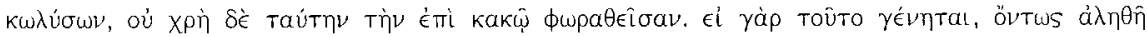

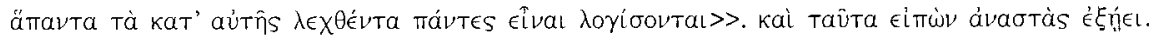

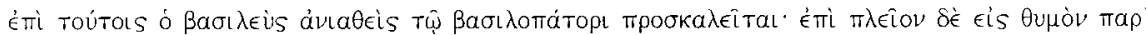

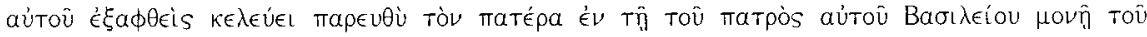

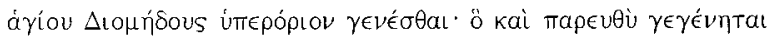

77 Die Vita hat "Basilopator", der korrekte Titel ist „Basileopator", vgl. ODB 1, 263f., s. v.

78 Weitere Beispiele: Vita Theod. Stud. (BHG 1754) cap. 27, col. 269B (Verbannung 809, vgl Pratsch, Theodoros 168); cap. 37, col, 288B-C (Verbannung 815, vgl. Pratsch, Theodoros $247-$ 249); Vita Symeonis iun. theol. (BHG 1692) cap. 95, p. 130-132 (Verbannung nach Palukiton); Vita Methodii (BHG 1278) cap. 5, col. 1248C (unter Michael II. nach Hagios Andreas, vgl. Zielke, Methodios 202-205); Vita Procopii Decapol. (BHG 1583) cap. 19, p. 319; Vita Theoph. conf. (BHG 1787z) cap. 50, p. 31,30-32,5.

79 Vgl auch Scheibelreiter, Gegner 61.64

80 Vgl. Apg 16. 23-34.

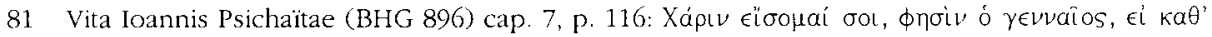

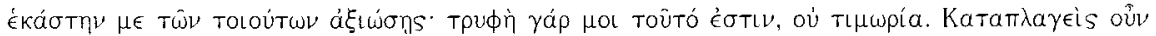

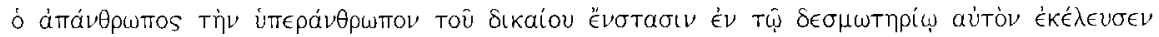
$\dot{\alpha} \sigma \phi a \lambda \omega \bar{s} \kappa a \theta \epsilon \iota p X \theta \tilde{\eta} \nu a t$ 
ser kurzen Darstellung wird der Peiniger noch nicht völlig überzeugt und für die andere Seite gewonnen, aber er verliert bereits seine Überzeugung und seinen Mut, was einen ersten Schritt auf dem Wege der Konversion des Peinigers darstellt.

Zum Motiv der „Überzeugung der Verfolger“ ist auch jene kurze Darstellung in der Vita des Euthymios von Sardeis (BHG 2145) zu rechnen, der zufolge Euthymios, der gerade verhört und gefoltert wurde, zu einem seiner Peiniger, einem Kanikleios, plötzlich folgendes sagte ${ }^{82}$ : "Ich hörte, daß deine Mutter und Schwester das Nonnenkleid genommen haben.' Der (Kanikleios) aber sagte sehr schroff: 'Ja.' Und der Heilige sagte: 'Die schönen Züge und die schöne Art der Frömmigkeit trägst auch du in dir!' Der (Kanikleios) aber war wie vom Donner gerührt durch den Spott des Seligen, und als hätte er einen Stein in den Mund genommen, der die Rede behindert, schloß er die Schlechtigkeit in Schweigen ein, ging zu den anderen und zog sich zurück."

Gregorios Dekapolites überzeugte nach der Darstellung seiner Vita ebenfalls seine Peiniger, zunächst die aufgebrachte Volksmenge, dann den Bischof von Hydrus (Otranto) in Kalabrien ${ }^{83}$ : „Die vom Bösen getriebenen Bewohner (sc. von Hydrus) warfen ihm vor, er, der Heilige, sei gekommen, um die Christen zu verraten, und bedrohten ihn mit dem Tode, ja sie verbanden ihm sogar den Kopf mit dem Schweißtuch und hatten vor, ihn eilig totzuprügeln. Der Heilige aber milderte durch sein inneres Gebet die wilde Gesinnung der Übeltäter und brachte sie davon ab, ihm etwas anzutun. Sie zerrten ihn also vor den damaligen Inhaber des Bischofsamtes, damit er das Urteil über ihn fälle. Als Gregorios aber dem Bischof unter die Augen gekommen war, entbot er diesem noch nicht einmal den Gruß, da er der Irrlehre (sc. dem Ikonoklasmus) anhing. Als er aber von seinen Bütteln Backenstreiche erhielt, sagte er: 'Ist es dir nach dem Sinn, o Bischof, schweigend zuzusehen, wie ich getötet werde?' Der aber vertrieb die Peiniger des Heiligen und bedrohte sie mit Geißelung. Der Heilige entriß sie jedoch jeder gefährlichen Züchtigung, indem er sich zu ihrem Fürsprecher beim Bischof machte."

Die Überzeugung der Verfolger ist recht häufig nur impliziert in der Weigerung des Henkers, den Heiligen zu züchtigen, wie etwa in dem nächsten Beispiel. Nach der Darstellung der Vita des Antonios des Jüngeren (BHG 142) wei-

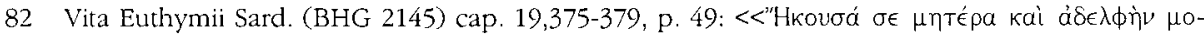

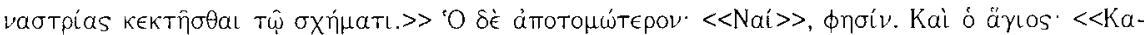

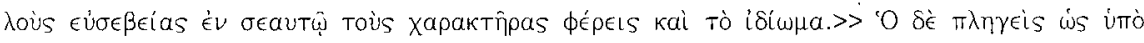

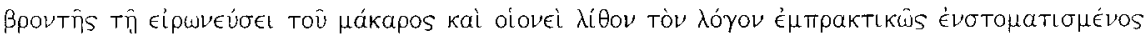

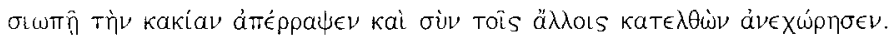

83 Vita Gregorii Decapolitae (BHG 711) cap. 33,5-16, p. 96-98. Übers. von M. Chronz. Vgl. dazu C. Mango, in: Byzantina 13,1 (1985) 635; Makris, Ignatios 97. 
gerte sich der Untergebene des epi ton deeseon Stephanos, den Antonios auszupeitschen ${ }^{84}$ : „Der mit der Auspeitschung des Heiligen beauftragte Diener warf sich auf die Erde und schrie, daß er etwas derartiges dem Diener Gottes nicht anzutun wage, selbst wenn er deshalb bis zu seinem Tode Gewalt erleiden müßte."

Recht ausgearbeitet findet sich das Motiv in der Vita des Theodoros Studites (BHG 1754). Der Mandator Niketas Alexiu wurde vom Kaiser damit beauftragt, Theodoros zu maßregeln und mit 100 Peitschenhieben zu züchtigen; in der Vita wird dann folgendes erzählt ${ }^{85}$ : Niketas begab sich nach Boneta und übermittelte Theodoros den Befehl des Kaisers. Der Heilige war sofort bereit, die Auspeitschung über sich ergehen zu lassen, und entledigte sich schon seiner Kleider. Als aber Niketas den vom Fasten ausgezehrten Körper des Abts sah, wurde er von Mitleid ergriffen. Er legte deshalb Theodoros ein Schaffell über die Schultern, auf das er dann mit der Peitsche schlug. Damit aber auch die Peitsche Spuren der Züchtigung aufwiese, fügte er sich mit einem kleinen eisernen Dorn selbst eine Wunde am Arm zu und benetzte mit seinem eigenen Blut den Riemen der Peitsche. Dann ging er schwer atmend hinaus (sc. aus dem Raum, wo die vorgebliche Züchtigung stattgefunden hatte) und tat so, als hätte er sich gerade einer großen Anstrengung unterzogen ${ }^{86}$.

Mitunter schreiten potentielle Peiniger des Heiligen auch gar nicht erst zur Tat, sondern werden schon im vorab von seiner Heiligkeit abgeschreckt und nehmen von ihren böswilligen Plänen Abstand $^{87}$.

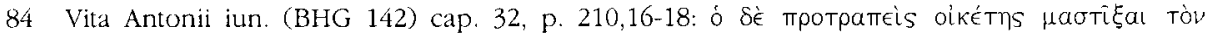

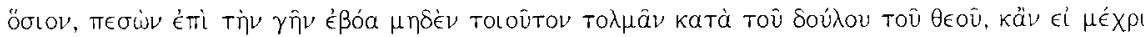
Өavátov ßíav úтоoтаí

85 Vita Theod. Stud. (BHG 1754) cap. 38, col. 288D - 289B; vgl. Theod. Stud, Ep. 112,43. Vgl dazu Pratsch, Theodoros 249-251; dens., Fact and Fiction 68-70

86 Weitere Beispiele: Vita Stephani iun. (BHG 1666) cap. 66, p. 167,9-168,7; nur angedeutet in cap. 31, p. 131,5-8; Vita Theod. Stud. (BHG 1754) cap. 41, col. 293B (Theophanes); Vita Nicet Medic. (BHG 1341) cap. 43-45, p. XXVIf. (Zacharias); Vita Methodii (BHG 1278) cap. 9 col. 1252C (vgl. Zielke, Methodios 206). - Überzeugung der Verfolger in Synaxarnotizen: Synax. Cpl. 100,28-31; 127/128,50-58 (dort ohne Namen): der hl. Theophilos überzeugt Kalybios.

87 "Potentielle" Peiniger: Vita Gregorii Decapolitae (BHG 711) cap. 21, p. 86 (slawische Räuber werden davon abgehalten, G. etwas zu tun); Vita Eliae Spelaeotae (BHG 581) cap. 12, p. 852F - 853 (räuberische Hirten, die sein Blut vergießen wollen, werden durch ein Wunder des $\mathrm{H}$ l. überzeugt); Vita Nili iun. (BHG 1370) cap. 5-6, p. 51f. (überzeugt Barbaren bzw. Araber durch seine fromme Antwort und sein Auftreten); Vita Athanas. Athon. (BHG 187) cap. 127, p. 61 (überzeugt einen Gegenspieler, der ihn töten will); Vita Mariae iun. (BHG 1164) cap. 10, p. 696D-E; Vita Lazari Galesiotae (BHG 979) cap. 10, p. 512 (Häretiker); Vita Theodori Syceotae (BHG 1748) cap. 76, p. 63f. (Protiktor Theodosios). 